\title{
Clinical governance - a fascinating problem made dull by rhetoric
}

\author{
Norman J Vetter \\ University of Wales College of Medicine, Cardiff, Wales, UK
}

\section{Introduction}

Most of the things done by the professionals in the health service have evolved over the years through personal experience, expert views and trial and error. Since the last World War, initially with the randomized controlled trials of TB therapy, there has been increasing interest in objectively measuring the effect of treatment on patients. The proponents of this approach suggest that, where tested, personal experience, even in those with a great deal of experience, does not always allow us to draw our evidence from sufficient numbers nor does it immunize us against unfounded enthusiasm for one treatment over another.

Unfounded enthusiasm, one of the commonest forms of bias in medicine, can best be overcome by a well-conducted clinical trial of one treatment against another, preferably with the patients randomly allocated to different treatment groups. The results, in terms of the patient's survival or wellbeing, are best measured by someone unaware of which treatment the patient received. Randomized controlled trials were most famously espoused by Archie Cochrane in the 1970s, and have been taken to be the gold standard in the past thirty years or more. There was, initially, a problem for professionals caring for elderly patients in this area, for many trials specifically excluded elderly people, or de facto excluded many of them, by stipulating, for instance, that patients should have only a single disease to be included. ${ }^{2}$

This question, of trying to discover the most effective treatment for patients and ensuring that this is the treatment chosen by all doctors, has taxed the minds of all of us for many years. The

Address for correspondence: N Vetter, Department of Epidemiology \& Public Health University of Wales College of Medicine, Heath Park, Cardiff, CF4 4XN, Wales, UK. latest approach to try to ensure this is through a concept known as clinical governance.

\section{What is clinical governance?}

Clinical governance was the centrepiece of an NHS white paper introduced soon after the Labour government came into office in the late 1990s. ${ }^{3}$ The white paper provided the framework to support local NHS organizations as they implemented a statutory duty of quality placed on them years before through the Conservative's 1990 NHS Act. Clinical governance made the Chief Executive responsible for the clinical quality of the work done in each organization, and was an attempt to make quality as important as price in the discussions of Trust and Health Authority Boards. Clinical governance puts the managers officially in charge of the professionals, even in their clinical work.

In 1998 Scally and Donaldson set out some of the background for clinical governance: 'A framework through which NHS organizations are accountable for continually improving the quality of their services and safeguarding high standards of care by creating an environment in which excellence in clinical care will flourish. ${ }^{4}$

The aim of clinical governance, according to the government, is to make sure that NHS Trusts and other organizations have:

\section{Clear lines of responsibility and accountability} for the overall quality of clinical care through:

- The Chief Executive, who has responsibility for assuring the quality of services provided by the Trust. Although it had been understood that the Chief Executive was in overall charge, this is the first time that it was spelled out

- A senior clinician responsible for making sure that systems for clinical governance are in 
place and monitoring their continued effectiveness. This is a difficult task with seemingly endless responsibilities, until we have some case law

- Formal arrangements for NHS Trust Boards to discharge their responsibilities for clinical quality. Again this is spelling out something that might have been thought to be obvious. Part of the problem has been that Trust Boards had to struggle very hard with decisions about how to make the budget balance at the end of the year. It will be interesting to see whether diverting their attention to quality will have an effect on balancing the books

- Regular reports to NHS Trust Boards on the quality of clinical care given the same importance as monthly financial reports. Trusts have produced regular reports on the quality of their clinical care for their Boards since they began. The important part of this new approach will be in the detail. If, for instance, some of the quality measures look at outcomes and are nationally set, the task will be considerably harder than if it is a general report on the audits undertaken in the trust

- An annual report on clinical governance

A comprehensive programme of quality improvement activities which includes:

- Full participation in audit programmes, including speciality and sub-speciality, external audit programmes endorsed by the Commission for Health Improvement (these will include the current four National Confidential Enquiries)

- Clinical audit systems in place in all clinical departments to ensure good practice, and that ideas and innovations can be introduced and evaluated

- Evidence-based practice supported and applied routinely in everyday practice

- Ensuring the clinical standards of National Service Frameworks and NICE recommendations are implemented

- Workforce planning and development (i.e. recruitment and retention of an appropriately trained workforce) fully integrated within the NHS Trust's service planning

- Continuing professional development: programmes aimed at meeting the development needs of individual health professionals and the service needs of the organization in place, and supported locally

- Appropriate safeguards to govern access to and storage of confidential patient information as recommended in the Caldicott Report on the Review of Patient-Identifiable Information

- Monitoring of clinical care with high quality systems for clinical record-keeping and the collection of relevant information

- Processes for assuring the quality of clinical care are in place and integrated with the quality programme for the organization as a whole

Once again the stringency of the programme will be all-important. All of these measures could be said to be part of every Trust's work, without labelling it with a fancy name. Measures to improve quality abound, and have done for many years, but measuring hard outcomes as a way of adjusting the work done in a trust is still quite rare and when it is performed, can be controversial. It seems clear that the term meant different things to different people after its first year in use ${ }^{5}$ but that finding of variability may, in itself have been advantageous as people realized the importance of standardizing the measures that they used.

\section{Clear policies aimed at managing risks:}

- Controls assurance which promotes self-assessment to identify and manage risks

- Clinical risk systematically assessed with programmes in place to reduce risk

Procedures for all professional groups to identify and remedy poor performance, for example:

- Critical incident reporting to ensure that adverse events are identified, openly investigated, lessons are learnt and promptly applied

- Complaints procedures, accessible to patients and their families - including patients and carers with disabilities - and fair to staff. Analysis should lead to weaknesses being identified, lessons learnt and recurrence of similar problems avoided

- Professional performance procedures which take effect at an early stage, before patients are harmed, and which help people to improve their performance whenever possible, in place and understood by all staff

- Staff supported in their duty to report any 
concerns about any colleagues' professional conduct and performance, with clear statements from the Board on what they expect of all staff. Clear procedures for reporting concerns so that early action can be taken to support the individual to remedy the situation

\section{Where does quality fit in?}

To my way of thinking, quality of care sits at the head of the hierarchy, which contains clinical effectiveness, clinical governance and other, similar ideas. Figure 1 shows this hierarchy and the questions that can be asked to identify which concept one is dealing with.

This hierarchy does not include another important factor, in relation to the care of elderly people, ethics. Thus clinical governance may define a particular course of action for the care of a patient, but the broader ethical dimension may include such problems as the wellbeing of relatives and other carers. At the present time there is some confusion about how to resolve these problems. ${ }^{6}$

Within the hierarchy, clinical effectiveness can be recognized as the process by which one decides 'Have I made the patient better?' This question is asked in relation to treatment or prevention or rehabilitation. On occasion one needs to ask 'Have I stopped the patient from getting any worse?' It is not quite as simple a question as it seems to be at first sight, for some patients improve without treatment, others perish on the best available. The question might be better framed 'Is the group with Treatment A better overall than that with Treatment B?' For prevention, the question can be modified to 'Is the group of people with Treatment A better as a result of preventative action than the group with $\mathrm{B}$, which did not receive it?'

Two different processes feed clinical effectiveness. The first of these is evidence-based medicine, which is the process whereby we choose between the different possible approaches to treatment or prevention, doing the right thing. The second is audit and other forms of monitoring. These are means of checking that the 'thing' isolated by evidence-based medicine is, in fact, being carried out in practice. Audit contains within it a process for changing the existing way of doing things after the first cycle and double-checking that the changes worked on the next cycle. It is therefore, by its nature, a repetitive process. A single audit cycle has no wheels!

Audit has, on occasion, shown some important differences between the treatment of younger and older people. An example of this is in the National Prostatectomy Audit Steering Group, which showed that older men were more likely to suffer acute retention of urine than younger, ${ }^{7}$ suggesting that the service is relatively agist in its ability to pick up and deal with symptoms of prostatism at an early stage. The group also showed that people who were left until suffering acute retention were at greater risk of dying than those treated electively.

The hierarchy suggests that risk management and change management both feed directly into clinical governance. Risk management is of par-

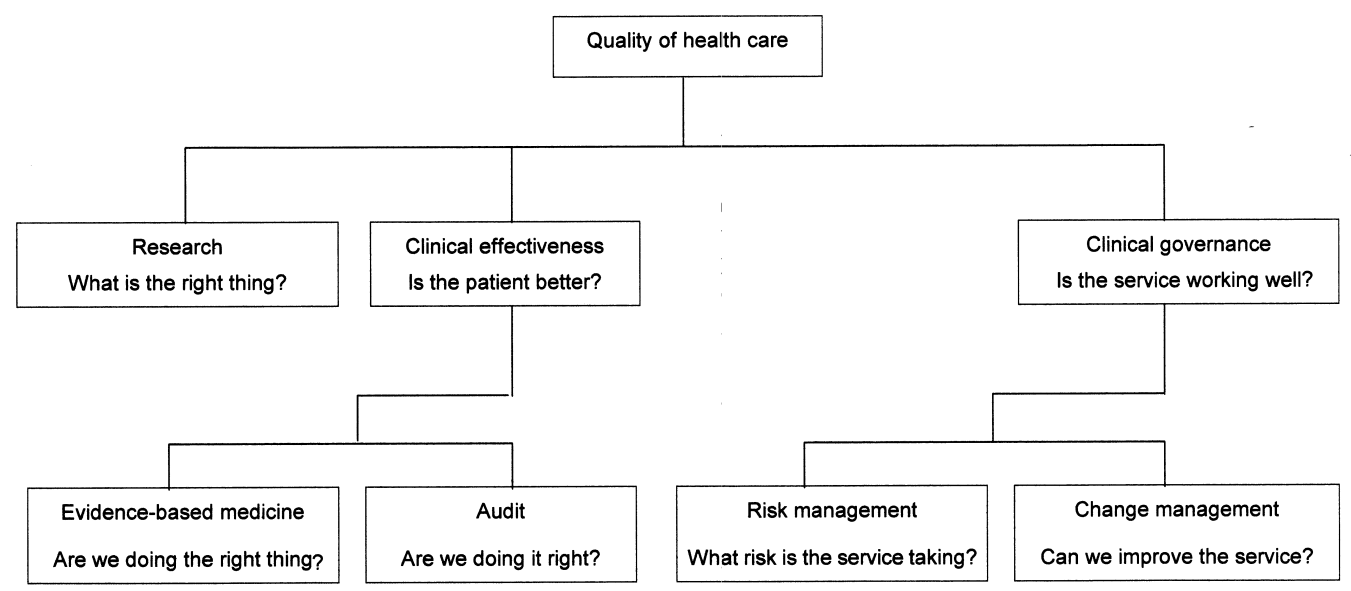

Figure 1. Hierarchy of quality in health care 
ticular importance when dealing with elderly patients. Sometimes the need of the organization to eliminate risk as far as possible may be at odds with the clinical need to take calculated risks and this can cause considerable tensions. ${ }^{8}$ Risk management is really a tool for reducing the risks to the organization and so can result in some rigidity in what the hierarchy will and will not allow. A surgeon 'with the heart of a lion', as I was taught in medical school, is not especially welcome in relation to risk management.

Change management is placed within the hierarchy because medicine is constantly in a state of flux. The correct approach one week can be completely overturned a week later, by more evidence or even a new analysis of old evidence. ${ }^{9}$ Managing change at all levels is therefore a central part of modern clinical practice, with all the corollaries to this of keeping up to date and understanding new skills.

In practice, one of the main functions of clinical governance has been to give a heading to a series of sub-headings relating to patient recovery. My own regret is that the phrase has taken the place of quality as the overarching model. The ideas it presently encloses are important, but it will be interesting to see if the phrase lasts another five years.

\section{References}

1 Cochrane AL. Effectiveness and efficiency. Random reflections on the health service. London: Nuffield Provincial Hospitals Trust, 1972.

2 Keith SJ. Evaluating characteristics of patient selection and dropout rates. J Clin Psychiatry 2001; 62 (suppl 9): 11-14.

3 Department of Health. The new NHS, Stationery Office (Cm 3807), 1997.

4 Scally G, Donaldson LJ. The NHS's 50th anniversary. Clinical governance and the drive for quality improvement in the new NHS in England. BMJ 1998; 317(7150):61-65.

5 Franks A. How goes the night, watchman? An overview of the first annual clinical governance reports (1999/2000) from acute trusts in an English NHS region. J Manag Med 2001; 15: 220-26.

6 Gallagher P, Clark K. The ethics of surgery in the elderly demented patient with bowel obstruction. $J$ Med Ethics 2002; 28: 105-108.

7 Pickard R, Emberton M, Neal DE. The management of men with acute urinary retention. National Prostatectomy Audit Steering Group. $\mathrm{Br} \mathrm{J}$ Urol 1998; 81: 712-720.

8 Waring A. Constructive risk in the care of the older adult: a concept analysis. Br J Nurs 2000; 9: 916-21, 924.

9 Freeman CD, Strayer AH. Mega-analysis of meta-analysis: an examination of meta-analysis with an emphasis on once-daily aminoglycoside comparative trials. Pharmacotherapy 1996; 16: 1093-1102. 